\title{
LAS ENTIDADES EMISORAS DE VALORES NEGOCIABLES EN BOLSA
}

Fernando Vidal Ramírez

\section{Premisa}

Los títulos negociables en la Bolsa, sea en la Rueda o en los mecanismos establecidos para ordenar el Mercado Extrabursátil, deben ser emitidos por personas jurídicas debidamente constituidas. Por eso, el presente estudio lo vamos a dedicar a la consideración de tales entidades, entre las que quedan comprendidas el propio Estado y las del Sector Público, así como las sociedades anónimas que conforman el Sector Privado.

\section{Las entidades del Sector Público}

Según el Art. 113 de la Constitución Política, "el Estado ejerce su actividad empresarial con el fin de promover la economía del país, prestar servicios públicos y alcanzar los objetivos de desarro1lo". En armonía con este precepto, mediante Decreto Legislativo $\mathrm{N}^{\circ} 216$, de 12 de junio de 1981, se ha puesto en vigencia la Ley que regula la actividad empresarial del Estado según la cual el Estado actúa en el ámbito empresarial bajo las formas de empresas de derecho pública, empresas estatales de derecho privado, empresas de economia mixta y con participación accionaria en personas jurídicas de derecho privado.

\subsection{Las empresas de derecho múblico}

Las empresas de derecho público son personas jurídicas de derecho público que se rigen por su ley de creación, la que les asigna este status expresamente y gozan de las atribuciones propias de los entes públicos o del imperium, característica del Derecho Público, pudiendo actuar también sin ejercer el ius imperium.

Estas empresas están facultadas para adoptar el Plan Contable 
Nacional, que rige para las demás formas de la actividad empresarial del Estado y están sometidas a las normas que anualmente entran en vigencia con la Ley Anual del Presupuesto de la República y a las de control establecidas por la Ley del Sistema Nacional del Control.

Los trabajadores se rigen por el régimen laboral del Sector Privado pero, en lo relativo a la participación en los beneficios, no rige el sistema de las acciones laborales.

Pueden ser creadas como sociedades a nónimas y su capital social estar representado por títulos accionarios emitidos por la respectiva empresa a nombre del Estado, representado por el Fondo Nacional de Financiamiento de la Actividad Empresarial del Estado.

Sólo pueden ser disueltas y declaradas en liquidación mediante ley expresa.

\subsection{Las empresas estatales de derecho privado}

Las empresas estatales de derecho privado son personas juridicas de derecho privado, constituidas originalmente o reorganizadas como tales, cuyo capital pertenece totalmente al Estado. Estas empresas sólo pueden adoptar la forma de sociedades anónimas y se rigen por la Ley General de Sociedades.

En relación al régimen de la Ley General de Sociedades, tienen las siguientes excepciones: a) No tienen Consejo de Vigilancia, pero están obligadas a tener auditoría externa; b) Los representantes del Estado ante las Juntas de Accionistas son designados por el Ministro competente; c) Para los casos de aumento o disminución del capital, emisión de obligaciones, transformación, fusión o disolución de la sociedad, los representantes del Estado ante la Junta de Accionistas deben recabar autorización expresa en cuanto al sentido de la votación, así como también para la elección del Directorio; d) Para ser Director no constituye impedimento desempeñar funciones en la administración pública y en entidades con participación del Estado que tengan relación con las de la sociedad; c) La falta de pluralidad de socios no es causal de disolución;f) Los estatutos pueden establecer la intransferibilidad de las acciones. su 
inembargabilidad e inafectabilidad en prenda y en usufructo; $g$ ) Los estatutos pueden autorizar procedimientos especiales para la disolución y liquidación.

El Plan Contable Nacional rige para estas empresas, las que también están sometidas a las normas que a nualmente entran en vigencia con la Ley Anual del Presupuesto de la República, asi como a las normas de control establecidas por la Ley.

Los trabajadores se rigen por el régimen laboral del Sector Privado pero, en lo relativo a la participación en los beneficios, no rige tampoco el sistema de las acciones laborales.

El capital social está conformado por acciones emitidas a nombre del Estado, representado por el Fondo Nacional de Financiamicnto de la Actividad Empresarial del Estado.

\subsection{Empresas de economia mixta}

Las empresas de economía mixta son personas jurídicas de derecho privado que sólo pueden adoptar la forma de sociedades anónimas, en las cuales el Estado participa asociado con terceros en los capitales y en la dirección de la sociedad. En ellas, el Estado tiene una participación accionaria mayoritaria que le garantiza el control absoluto de las decisiones de toda índole en los órganos de gobierno de la sociedad; $o$, tiene una participación accionaria menor, con un mínimo del $20 \%$ o del capital social, pero goza de capacidad determinante conf erida por los estatutos sociales.

Estas empresas se rigen por la Ley General de Sociedades, aunque $\sin$ la obligación de tener Consejo de Vigilancia, pues al igual que las empresas de derecho público y las estatales de derecho privado están sometidas al régimen de control que establece la Ley de la Actividad Empresarial del Estado y a las normas a que se remite. En estas empresas los representantes del Estado ante la Junta de Accionistas los nombra el Ministro competente del sector correspondiente, quienes deben contar con autorización expresa para los casos de aumento o disminución del capital, emisión de obligaciones, transformación, fusión o disolución de la sociedad, así como también para la elección de los Directores; estos últimos no tienen impedimento por funciones que desempeñen en la admi- 
nistración pública y en entidades con participación del Estado que tengan relación con las de la sociedad.

Los trabajadores se rigen por el régimen laboral del Sector Privado y, en lo relativo a la participación en los beneficios, no rige tampoco el sistema de las acciones laborales.

2.4 Participación accionaria en personas juridicas de derecho privado

El Estado puede participar en el capital accionario de personas jurídicas de derecho privado, sin que necesariamente éstas deban ser tipificadas como empresas de economía mixta. El Estado, como socio, no goza de ninguna prerrogativa especial, y las sociedades se rigen por la Ley General de Sociedades.

\section{El Sector Prilado}

Las entidades emisoras del Sector Privado lo constituyen las personas juridicas de derecho privado organizadas como sociedades anónimas y sometidas al régimen de la Ley General de Sociedades. En estas entidades, como sociedades a nónimas que son, el capital está representado por acciones y se integra por aportes de los socios, quienes no responden de las deudas sociales.

3.1 Las sociedades anónimas en la Lev General de Sociedades.Caracterización

Como acabamos de indicar, las sociedades anónimas están sometidas al régimen de la Ley General de Sociedades, que no es sino la reestructuración de la Ley de Sociedades Mercantiles de 1966, al haberse incorporado a su articulado la normativa de las sociedades civiles no legisladas ya por el Código Civil.

La Ley se inspira en el principio contractualista al establecer que "por el contrato de sociedad quienes la constituyen convienen en aportar bienes o servicios para el ejercicio en común de una actividad econónica, en cualquiera de las formas reguladas por la presente Ley" (Art. 1, parágrafo 1) y que "el contrato social, debidamente inscrito, genera una persona jurídica de derecho privado" (Art. 3, parágrafo 1). A partir de estas normas básicas, todo el de- 
sarrollo legislativo de la sociedad en general, incluyendo el de la sociedad anónima, sigue la concepción contractualista que es el principio que la gobierna.

La sociedad anónima, conforme al Art. 75 de la Ley, puede constituirse de manera simultánea, en un solo acto por contrato entre los fundadores, o en forma sucesiva, por suscripción pública de las acciones. Puede también aumentar su capital por nuevos aportes de sus socios (Arts. 212 y 216) y también por suscripción pública de las nuevas acciones (Art. 215). La Ley le franquea también la posibilidad de emitir bonos convertibles en acciones y aumentar el capital por ese medio (Art. 218). De este modo, la Ley General de Sociedades, como su antecedente la Ley de Sociedades Mercantiles, y aún el Código de Comercio -que al decir de Montoya Manfredi (1) permitía las dos formas de constitución al no hacer referencia alguna sobre el particular, lo que conduce a que también hacía posible todas las formas de aumento de capital que hemos indicado - ha establecido la posibilidad de existencia de sociedades con el accionariado concentrado y con el accionariado difundido, estableciendo la necesidad del Consejo de Vigilancia para éstas últimas, en el Art. 188, cuando el número de accionistas fuera mayor de 50. Sin embargo, la sociedad anónima se caracteriza por una estructura cerrada, en la que predomina el accionariado concentrado, sea porque los accionistas están vinculados por nexos familiares o de grupo, en los que prima una comunidad de intereses excluyente.

Cuando se derogó el articulado del Código de Comercio por la Ley de Sociedades Mercantiles, cuyas normas están ahora contenidas en la Ley General de Sociedades, se mantuvo, al lado del principio contractualista el de la affectio societatis, que tiene su origen en el Derecho Romano y que romanistas como Iglesias (2) lo explican vinculándolo a la consensualidad del contrato de sociedad $y$, más precisamente, en el consentimiento constante y duradero para la permanencia de la sociedad. La doctrina contemporánea ve en la affectio societatis la intención de vincularse para la obtención de un beneficio común entre los socios.

(1) Sociedades Anónimas, pág. 60.

(2) Derecho Romano. Instituciones de Derecho Privado, pág. 449. 
De las formas de constitución previstas es incuestionable que la de la constitución simultánea ha sido y sigue siendo en nuestro medio la de mayor acogida. En ella se da, acentuadamente, el carácter contractual de la sociedad y la primacía de la affectio societatis, habiendo contribuido a la estructura cerrada de la sociedad y a la concentración accionaria en los grupos familiares o en los que se forman dentro de una comunidad de intereses excluyente. Es más, esta forma de constitución se sustenta también en el temor a la apertura de la sociedad y conduce a que no se recurra a la oferta pública de acciones que coadyuve a la difusión del accionariado. En estas sociedades el grupo que tiene el control llega a solicitar la admisión a cotización de las acciones en la Bolsa pero reteniendo la proporción suficiente para no perderlo ni ponerlo en riesgo.

La incorporación expresa de la constitución sucesiva y del aumento de capital mediante oferta pública, así como por la conversión de obligaciones, en nuestro ordenamiento societario a partir de 1966, puede llevar a considerar que propició la existencia de sociedades abiertas, pese a los principios contractualista y de la affectio societatis que lo informan, aspectos que vamos a considerar al ocuparnos de las sociedades abiertas. Sin embargo, debe señalarse que no es significativa la cantidad de sociedades que se han constituido de manera sucesiva, aunque tengan mayor relevancia los aumentos de capital mediante oferta pública de las acciones, pues también en estos casos los fundadores y el grupo que ha tomado el control cuidan que sólo salga a la suscripción pública una proporción del capital accionario que no les haga peligrar el control.

Nosotros no cuestionamos el derecho de los fundadores de tomar y preservar el control de la sociedad, ni aún cuando en alguna medida se haya abierto la sociedad y exista una relativa dispersión del accionariado. La Ley misma cuida de equilibrar las relaciones entre el grupo de control y los demás accionistas mediante el régimen de protección a los accionistas minoritarios. Lo que hemos pensado siempre y seguiremos pensando es en la necesidad de la reforma de la Ley para normar la constitución de sociedades de capital abierto, ya que, en nuestro medio, no por el hecho de que una sociedad anónima cotice en Bolsa es una sociedad abierta. La sociedad abierta, como veremos a continuación, debe serlo estructuralmente en su constitución y desenvolvimiento. 


\subsection{La sociedad anónima abierta}

Por lo general la doctrina y el Derecho Comparado para conceptualizar, a las denominadas sociedades abiertas, parte de la consideración de si se han constituido integrando el capital mediante la oferta pública de sus acciones o si, ya constituidas, han recurrido a la oferta pública para el aumento de su capital. En consonancia con este criterio, se considera también sociedades abiertas a las que cotizan sus acciones en la Bolsa, esto es, a las que se ofrecen a la inversión privada y a servir de canalización del ahorro interno, financiándose, por ello, por este medio. Nosotros estamos de acuerdo con estos elementos determinativos de la sociedad abierta y una vez que ésta se configura debe quedar comprendida dentro de un régimen legal específico en el que se prescriba el funcionamiento de sus órganos y los derechos de los accionistas y la conciliación de éstos con los intereses de la sociedad.

La cuestión que habrfa que plantear es de si bajo estas premisas la sociedad abierta se compadece con el principio contractualista y el de la affectio societatis que tradicionalmente son los informantes de nuestro ordenamiento societario. Creemos que el principio contractualista en nada se ve afectado, pues la constitución sucesiva si bien está precedida de la suscripción del Programa de Fundación, como bien lo señala Morles Hernández (3), tal suscripción no modifica la calificación contractual del acto de constitución, pues el contrato se compone de dos manifestaciones de voluntad expresadas en momentos separados: la de por los suscriptores al suscribir el prospecto y la de la asamblea constitutiva. Tampoco el aumento de capital mediante oferta pública de las acciones afecta el principio contractualista, pues con ella se da paso a un contrato de adhesión con cláusulas generales de contratación, que, incluso, están autorizadas por autoridad administrativa, como es la CONASEV (Arts. 1390, 1392 y 1393 del Código Civil).

Consideramos que el principio de la affectio societatis tampoco se afecta en la sociedad abierta, máxime si este principio tiene una expresión más evidenciada en la sociedad anónima respecto de la sociedad cerrada o de accionariado concentrado. En una y otra, por el hecho de estar el capital representado en acciones y que es

(3) Curso de Derecho Mercantil, T. II, pág. 578 
en estos títulos en los que radica la calidad de socio, ésta es intuito pecuniae y es este modo de vinculación al que determina la affectio societatis. Estamos con la doctrina que no ve en la affectio societatis una vinculación intuito personae (4).

Planteadas las precedentes consideraciones de orden personal y tomando en cuenta el excelente trabajo de Maria Luisa Gubbins (5) y otras fuentes, como el Comentario de la Bolsa de Rosario (6) al interesante y novedoso estudio de la Bolsa de Madrid sobre La Nueva Sociedad Anónima (7), los criterios para la determinación de la sociedad anónima abierta se sustentan en lo que ya hemos dejado expuesto en cuanto a las sociedades que recurren a la oferta pública de sus acciones y a su cotización en Bolsa, así como también en el número de accionistas o en una proporción de su capital distribuido entre un número determinado de accionistas, instrumentándose esta participación accionaria mediante acciones desprovistas de voto.

3.3 La calificación de las sociedades anónimas como abiertas en la legislación peruana

Complementando las disposiciones de la Ley General de Sociedades y aún modificando - pero no "reglamentando"-, mediante Decreto Supremo $N^{\circ}$ 089-87-EF, de 6 de abril de 1987, se han dictado disposiciones para la calificación de sociedades anónimas como sociedades abiertas. Decimos que no se trata de una reglamentación, aunque así lo indica el Art. 1, por cuando el Decreto Supremo $N^{\circ}$ 089-87-EF ha sido promulgado al amparo del inc. 20 del Art. 211 de la Constitución Politica que confiere al Presidente de la República la atribución de dictar "medidas extraordinarias en materia económica y financiera, cuando así lo requiera el interés nacional y con cargo de dar cuenta al Congreso" y no del ejercicio de la potestad de reglamentar las leyes, que consagra el inc. $11 \mathrm{del}$

(4) Sobre estos aspectos véase el exhaustivo análisis realizado por María Luisa Gubbins, en La Sociedad Anónima Abierta en la Ley General de Sociedades. Tesis de Bachiller en Derecho. Pontificia Universidad Católica del Perú, Lima, 1987.

(5) Ibidem,

(6) Memoria de la 11a. Asamblea General FIABV, Rosario, T. II, págs. 391 y sgtes.

(7) Ibidem, T. II, págs. 341 y sgtes. 
mismo Art. 211. Las normas en referencia y que van a ser objeto de nuestro estudio, independientemente de si están o no dentro del marco que establece el inc. 20 para los llamados "decretos de emergencia", constituyen normas legales en sentido material.

Las normas dictadas han establecido la calificación de las sociedades anónimas como sociedades abiertas adoptando el criterio sustentado en la cotización en Bolsa de sus acciones en las condiciones que precisan los Arts. 27 y 28 .

Según el Art. 27, "serán calificadas como sociedades abiertas las que tengan sus acciones ordinarias inscritas en Bolsa y además que el treinta por ciento $(30 \%)$ como mínimo de su capital social se encuentre difundido entre el público". Agrega el mismo numeral que "para estos efectos se entiende como "el público" a un número mínimo de 50 accionistas que individualmente no posea más del tres por ciento $(3 \%)$ del capital social". Como puede apreciarse la calificación depende de requisitos concurrentes, como son la cotización en Bolsa de las acciones, la difusión del $30 \%$ del capital accionario en un mínimo de 50 inversionistas, de los cuales cada uno de ellos, sea persona natural o jurídica, no podrá ser titular de más del 3\% del capital accionario.

La calificación en base a los requisitos expuestos, según el mismo Art. 27, tendrá una vigencia de 2 años, al término de la cual puede renovarse - interpretamos que por un plazo de vigencia también de 2 años-- si la difusión del accionariado ha aumentado en $3 \%$ hasta alcanzar un máximo de $49 \%$, y el número de accionistas sigue siendo de 50 ó más. No se desprende de la norma qué ocurre con la calificación después del $4^{\circ}$ año de vigencia, lo que tendrá que ser aclarado con la reglamentación que el Art. 2 le encarga a la CONASEV. Consideramos que si con esta calificación se ha pretendido promover la difusión del accionariado, las normas dictadas han debido establecer algún tipo de incentivo o estímulo a las sociedades emisoras, máxime si se da a la CONASEV mayor injerencia en aspectos internos y de relación con sus accionistas, como veremos más adelante.

El Art. 28 ha autorizado la emisión de acciones sin voto y cuando éstas sean colocadas a través de la Bolsa en una proporción superior al $50 \%$ del capital social y en un número superior a 100 
accionistas, la sociedad emisora podrá ser calificada como sociedad abierta. El Art. 28 llama acciones ordinarias a las acciones con voto y "acciones preferenciales sin voto" a las que mediante su colocación en Bolsa van a permitir la calificación de sociedad abierta y cuya creación requiere de las formalidades exigidas para la modificación del estatuto (Art. 30). Se ha introducido, por este medio, sustanciales modificaciones a la Ley General de Sociedades, particularmente al Art. 109, en cuanto enumeraba como uno de los derechos esenciales del accionista el de votar en las Juntas Generales, ya que sólo se reconoce a los titulares de estas acciones el derecho a concurrir con voz, pero sin que su presencia deba ser tomada en cuenta para el cómputo del quórum (Art. 29, 4to. parảgrafo). Sin embargo, en las hipótesis previstas en el Art. 30, esto es, durante la suspensión de la cotización en Bolsa de los títulos teniendo aún la sociedad la calificación de abierta, o si la perdiera, o cuando la junta sea convocada para tratar sobre la transformación, fusión o disolución de la sociedad, el traslado de la sede, el retiro de la cotización en Bolsa, o la reducción del capital, los acuerdos que se adopten requieren del voto aprobatorio de por lo menos el $30 \%$ del número de los titulares de estas "acciones preferentes".

Consideramos que el criterio de calificación basado en la emisión de las acciones sin voto resulta mucho más positivo que el anterior, en cuanto les va permitir a las sociedades emisoras utilizar el mercado de valores y la Bolsa como fuente de financiamiento, pues estas acciones se constituyen únicamente en títulos de renta, en los que se evidencia un intuito pecumiae. En efecto, según el Art. 29 las acciones sin voto gozan de una rentabilidad anual garantizada no inferior al $50 \%$ a la tasa de interés vigente para las operaciones activas a largo plazo del sistema financiero, siempre que, desde luego, la sociedad obtenga utilidades en el ejercicio correspondiente. La renta señalada, según el mismo Art. 29, constituye un pago a cuenta del importe correspondiente al dividendo que corresponda $y$, en caso que el ejercicio arroje pérdidas o las utilidades estén por debajo de los niveles requeridos para cubrir la renta preferencial, su importe será pagado al accionista preferente y puede ser deducido como gasto en el ejercicio correspondiente.

La calificación de sociedad abierta, como hemos ya advertido, trae una mayor injerencia de la CONASEV en aspectos internos de la vida societaria y de relación con sus accionistas, pues se 362 
han introducido otras modificaciones a la Ley General de Sociedades.

En primer lugar, en relación a los Art. 125 y 126 de la Ley, pues el Art. 31 faculta a la CONASEV a convocar a la Junta General de Accionistas ex officio. Como se sabe, la Ley General de Sociedades señala que corresponde al Directorio convocar a la Junta General Extraordinaria cuando lo estime conveniente a los intereses sociales o lo solicite notarialmente un número de socios que represente, al menos, la quinta parte del capital pagado, debiendo efectuar la convocatoria dentro de los 30 dias siguientes a la solicitud (Art. 124). Si la solicitud fuese denegada o si transcurriese el plazo de 30 dias sin efectuarse la convocatoria, el Art. 125 de la Ley franqueaba a los accionistas solicitantes a recurrir al Juez, intervención judicial que ha sido suplida por la de la CONASEV, habiéndose facultado, además, a "cualquier accionista" a solicitar la convocatoria, sea titular de acciones con o sin voto, pues el Art. 31 no distingue. De otro lado, como se sabe, el Art. 126 faculta al titular de una sola acción - con voto- a recurrir al Juez para que ordene la convocatoria a Junta General Ordinaria o a que se traten los asuntos que son propios de dicha Junta, cuando se han omitido, habiéndose también facultado a la CONASEV a convocarla de oficio $u$ ordenar que se traten todos los asuntos inherentes a la Junta General Ordinaria, así como también a "cualquier accionista".

En segundo lugar, en relación al Art. 188 de la Ley que dispone la necesaria presencia de un Consejo de Vigilancia en las sociedades anónimas, cuando el número de accionistas fuera mayor de 50 o su capital no menor de 20 millones de soles -..en la actualidad $20 \mathrm{mil}$ intis, lo que pone de manifiesto un error de técnica legislativa de no usar términos de referencia que resulten constantes-, y cuando se haga oferta de acciones para su suscripción pública, sea para la constitución social o para el aumento del capital, salvo que el Directorio se elija por unanimidad o con participación de los accionistas minoritarios, que la sociedad tenga auditoría externa permanente a cargo de contadores públicos colegiados. El Art. 32, cuando la sociedad ha sido calificada como abierta, prescribe la necesaria existencia de un Consejo de Vigilancia, elegido en votación secreta y en el que deben estar representadas la minoría, sin 
especificar si esta minoría corresponde a la de los titulares de acciones con o sin voto, o a la de ambos.

El Art. 33 prescribe la obligación de proporcionar los informes y explicaciones que fuera de Junta General, le soliciten accionistas que representen por 10 menos el $3 \%$ del capital pagado, siempre que no se trate de asuntos confidenciales y, en el caso de discrepancia sobre el carácter confidencial de la información, le corresponde dirimir a la CONASEV. Consideramos que la norma se refiere a los titulares de las acciones sin voto, pues del derecho de las acciones con voto se ocupa el Art. 132 de la Ley General de Sociedades.

Por último, el Art. 35 faculta a las sociedades abiertas a emitir obligaciones convertibles en acciones, las que deberán ser cotizadas en Bolsa. Agrega que la decisión para hacer esta misión importa automáticamente el acuerdo de aumento de capital cuando dicha conversión se produzca y el de emisión de las acciones necesarias para proceder al canje de los títulos cuya conversión soliciten sus tenedores, lo que resulta superfluo si se tiene en cuenta que la Ley General de Sociedades, en su Art. 218, ha previsto el aumento de capital mediante la emisión de obligaciones convertibles en acciones. 